\title{
Racial/Ethnic Differences in Mental Health, Substance Use, and Bullying Victimization Among Self-Identified Bisexual High School-Aged Youth
}

\author{
Brian A. Feinstein, PhD, ${ }^{1}$ Blair C. Turner, MPH, ${ }^{1,2}$ Lauren B. Beach, JD, PhD, ${ }^{1,2}$ \\ Aaron K. Korpak, ${ }^{1,2}$ and Gregory Phillips II, MS, PhD ${ }^{1,2}$
}

\begin{abstract}
Purpose: Sexual minority youth are at increased risk for mental health problems and substance use, and accumulating evidence indicates that bisexual youth are at greatest risk. However, bisexual youth are not a homogenous group and scholars have called for greater attention to the intersections of multiple marginalized identities. As such, we examined racial/ethnic differences in mental health (sadness/hopelessness and suicidal ideation), substance use (cigarette use, binge drinking, marijuana use, and other illicit drug use), and bullying (in-person and electronic) among self-identified bisexual high school-aged youth (overall and by sex).

Method: Data from the local versions of the Youth Risk Behavior Survey were pooled across jurisdictions and years (2011-2015), resulting in an analytic sample of 18,515 bisexual youth who were racially/ethnically diverse.

Results: Black and Hispanic bisexual youth were less likely to report in-person and electronic bullying than White bisexual youth. In addition, Black bisexual youth were less likely to report sadness/hopelessness and suicidal ideation than White, Hispanic, and Other race/ethnicity bisexual youth. Black bisexual female youth were also less likely to report cigarette use, binge drinking, and other illicit drug use than White bisexual female youth. In contrast to most of our findings, Black bisexual youth were more likely to report marijuana use than White bisexual youth. Most of the significant racial/ethnic differences in mental health and substance use remained significant after controlling for bullying.
\end{abstract}

Conclusion: These findings highlight the heterogeneity of bisexual youth and the need to consider multiple marginalized identities to understand the health disparities affecting this diverse population.

Keywords: bisexual, bullying, ethnicity, mental health, race, substance use

\section{Introduction}

$\mathbf{S}^{\mathrm{s}}$ EXUAL MINORITY (SM) youth are at increased risk for mental health problems and substance use compared with their heterosexual peers, ${ }^{1,2}$ and mental health problems are commonly comorbid with substance use among SM youth. ${ }^{3}$ Historically, researchers have treated SM people as a homogenous group, but there is substantial within-group heterogeneity in their health. For example, bisexual youth are at increased risk for depression, suicidality, and substance use compared with gay, lesbian, and heterosexual youth. ${ }^{4-13}$ However, bisexual youth are not a homogenous group and scholars have called for greater attention to the intersections of multiple marginalized identities. ${ }^{14,15}$
Scholarship on intersectionality has drawn attention to the ways in which people with multiple marginalized identities are affected by intersecting systems of oppression. ${ }^{15,16}$ For example, bisexual youth of color are not only affected by heterosexism and monosexism (i.e., the belief that heterosexuality and/or homosexuality are superior to or more legitimate than bisexuality), they are also affected by racism, and this has the potential to influence their health relative to White bisexual youth. However, the specific ways in which holding multiple marginalized identities influences health remain unclear. Some researchers have suggested that SM people of color experience additional stress due to having multiple marginalized identities, which can overburden coping resources and lead to negative health outcomes. ${ }^{17,18}$

\footnotetext{
${ }^{1}$ Institute for Sexual and Gender Minority Health and Wellbeing, Northwestern University, Chicago, Illinois.

${ }^{2}$ Department of Medical Social Sciences, Feinberg School of Medicine, Northwestern University, Chicago, Illinois.
} 
Others have suggested that SM people of color have unique strengths (e.g., higher religiosity) that contribute to resilience. ${ }^{19,20}$

Previous studies on bisexual youth have been limited in their ability to examine racial/ethnic differences due to small samples and limited diversity. In exceptions, recent studies have examined the extent to which sexual orientation disparities in alcohol use were present across racial/ethnic groups. One study found that bisexual and White youth were more likely to report alcohol use than heterosexual and racial/ethnic minority youth, respectively, but found limited evidence of sexual orientation differences being moderated by race/ethnicity. ${ }^{13}$ Another study found that Black, Latina, and White bisexual female youth all reported higher drinking frequency than heterosexual female youth of the same race, and Black and Latino bisexual male youth reported higher drinking frequency than heterosexual male youth of the same race. ${ }^{21}$ However, none of these group differences remained significant after controlling for bullying. These studies provide a foundation for understanding sexual orientation disparities in alcohol use across racial/ethnic groups, but additional research is needed to examine racial/ethnic differences in the health of bisexual youth in particular.

We are not aware of any studies that have examined racial/ethnic differences in substance use specifically among bisexual youth, but several have done so in samples of SM male youth. One study found that White SM male youth were more likely to be diagnosed with nicotine and alcohol dependence than Black SM male youth. ${ }^{22}$ Another study found that White SM male youth were more likely to report alcohol and club drug use than Black and Latino SM male youth. ${ }^{8}$ These findings suggest that racial/ethnic minority status may be protective against substance use among SM youth.

In contrast, previous research on racial/ethnic differences in the mental health of SM youth has produced mixed results. $^{23}$ Some studies have found that White SM youth are more likely to report suicidal ideation ${ }^{22,24}$ and to be diagnosed with a major depressive episode ${ }^{22}$ than Black SM youth, but one study also found that White SM youth were less likely to report feeling sad (compared with Latino SM youth) and to have made a suicide attempt (compared with other race/ethnicity SM youth). ${ }^{24}$ Another study provided conflicting evidence in a sample of LGB emerging adults. ${ }^{25}$ White LGB emerging adults were more likely to report depression (compared with Black, Latino, and Asian LGB individuals) and suicidal ideation (compared with Latino LGB individuals), but they were less likely to report suicide attempts (compared with Black and multiracial LGB individuals) and self-harm (compared with multiracial LGB individuals). ${ }^{25}$ In sum, previous research on racial/ethnic differences in the mental health of SM youth has produced mixed results, and none of these studies has focused specifically on bisexual youth.

In addition to being at increased risk for mental health problems and substance use, bisexual youth are also at increased risk for bullying. ${ }^{26}$ Data from large national samples have revealed that bisexual youth are more likely to report being bullied than heterosexual youth, ${ }^{26,27}$ and in-person and electronic bullying are both risk factors for mental health problems and substance use. ${ }^{28-31}$ There is also evidence that
SM youth who experience both in-person and electronic bullying may be at greatest risk for negative health outcomes. ${ }^{28}$ However, little is known about racial/ethnic differences in bullying among SM youth. A recent study found that Black, Hispanic, and White SM youth were all more likely to report bullying than heterosexual youth of the same race/ethnicity. ${ }^{21}$ There is also evidence that White LGBT individuals are more likely to experience cyberbullying than African American and Asian LGBT individuals. ${ }^{32}$ In contrast, another study did not find ethnic differences in school victimization during adolescence among LGBT young adults. $^{31}$ Given that there may be racial/ethnic differences in bullying, it is important to account for these experiences in analyses of racial/ethnic differences in health. Doing so has the potential to lead to a more nuanced understanding of racial/ethnic differences in health, including the extent to which they are explained by confounding variables.

In sum, bisexual youth are at increased risk for mental health problems, substance use, and bullying. However, bisexual youth represent a heterogeneous group and little is known about racial/ethnic differences in this population. As such, the primary goal of the present study was to examine racial/ethnic differences in mental health (sadness/hopelessness and suicidal ideation) and substance use (cigarette use, binge drinking, marijuana use, and other illicit drug use) among bisexual youth. Given that bullying is a risk factor for mental health problems and substance use, we also examined racial/ethnic differences in in-person and electronic bullying and whether racial/ethnic differences in health persisted after controlling for bullying.

\section{Methods}

\section{Data source}

The Youth Risk Behavior Survey (YRBS) is a biennial national survey that has been conducted by the Centers for Disease Control and Prevention since 1991 to collect health data on students in grades $9-12 .{ }^{33}$ We used data from local versions of the YRBS, which are administered on a state, large urban school district, or county level by departments of education or health. In this implementation, jurisdictions use a two-stage cluster sample design to identify a sample of students. ${ }^{33}$ First, schools are selected with a probability proportional to their enrollment. Second, classes of a required subject or during a required period are randomly selected, and all students within these classes are eligible to participate. A new sample is selected in this manner each year that the survey is administered.

\section{Analytic sample}

Local YRBS data were pooled across jurisdictions (city and state) and years (biennially from 2005 to 2015). Jurisdictions that asked at least one question about sexual orientation were included. The entire data set consists of 47 jurisdictions across 10 years and 541,410 youth. The present analyses included 2011-2015 data from 85 jurisdiction-years that assessed sexual identity (Supplementary Table S1), limited to students who identified as bisexual $(N=19,379)$. Youth were also excluded if they were missing data on demographic variables, resulting in a sample of 18,515 bisexual 
youth. The study was approved by the Northwestern University Institutional Review Board.

\section{Measures}

Demographics. Participants were asked to report their sexual orientation (identity), race/ethnicity, sex, and age. Sexual orientation (identity) was assessed with the following question: "Which of the following best describes you?" Response options were as follows: heterosexual (straight), gay or lesbian, bisexual, and not sure. Race and ethnicity were assessed with two questions. Participants were asked if they identified as Hispanic or Latino, and then they were asked to select all races that applied from the following list: American Indian or Alaska Native, Asian, Black or African American, Native Hawaiian or other Pacific Islander, and White. Responses were used to create four groups: (1) White; (2) Black or African American; (3) Hispanic or Latino; and (4) Other. Sex was assessed with the following question: "What is your sex?" Response options were male or female. Age was assessed with the following question: "How old are you?" Response options ranged from "12 years old or younger" to "18 years old or older."

Mental health. Participants were asked two questions about their mental health (sadness/hopelessness and suicidal ideation) in the past year. First, they were asked, "During the past 12 months, did you ever feel so sad or hopeless almost every day for two weeks or more in a row that you stopped doing some usual activities?" Then, they were asked, "During the past 12 months, did you ever seriously consider attempting suicide?" Response options for both questions were yes or no.

Substance use. Participants were asked a series of questions about their substance use (lifetime cigarette use, pastmonth binge drinking, lifetime marijuana use, and lifetime other illicit drug use). First, they were asked, "Have you ever tried cigarette smoking, even one or two puffs?" Response options were yes or no. Then, they were asked, "During the past 30 days, on how many days did you have 5 or more drinks of alcohol in a row, that is, within a couple of hours?" Response options ranged from "0 days" to "20 or more days" and were dichotomized $(0=0$ days, $1=1$ or more days). Finally, they were asked a series of questions about their use of marijuana, cocaine, heroin, methamphetamines, and ecstasy during their life. Response options were yes or no. We created two variables: any marijuana use (yes/no) and any other illicit drug use (yes/no).

Bullying. Participants were asked two questions about bullying victimization (in-person and electronic) in the past year. First, they were asked, "During the past 12 months, have you ever been bullied on school property?" Then, they were asked, "During the past 12 months, have you ever been electronically bullied? (Count being bullied through e-mail, chat rooms, instant messaging, websites, or texting.)" Bullying was defined as: "When 1 or more students tease, threaten, spread rumors about, hit, shove, or hurt another student over and over again. It is not bullying when 2 students of about the same strength or power argue or fight or tease each other in a friendly way." Response options for both questions were yes or no.

\section{Statistical analysis}

Data cleaning and recoding was conducted in SAS software version 9.4 (SAS Institute Inc., Cary, NC). Analyses were carried out using SAS-Callable SUDAAN version 11.0.1 (Research Triangle Institute, Research Triangle Park, NC) to weight estimates and account for the complex sampling design of the YRBS. The YRBS data weights adjust for student nonresponse and distribution of students by grade, sex, and race/ethnicity in each jurisdiction. ${ }^{33}$

First, descriptive statistics were calculated for the full sample and each racial/ethnic group. Second, two sets of multivariable logistic regression models were used to estimate the odds of each outcome associated with race/ethnicity and sex. The first set of models controlled for age and survey year, and the second set of models also controlled for inperson and electronic bullying. For both sets of models, White and male youth served as the reference groups. Third, to test whether associations between race/ethnicity and outcomes differed by sex, we added interaction terms (race/ethnicity $\times$ sex). When the overall $F$-test was significant, we probed the significant interactions to compare the racial/ethnic groups separately for male and female youth. Only significant interactions are reported. Fourth, in a set of supplementary analyses, we changed the race/ethnicity reference group to Black youth to compare them with Latino and Other race/ethnicity youth. Finally, in a set of sensitivity analyses, we excluded potentially "mischievous responders" (i.e., youth who provide extreme and potentially untruthful responses to multiple questions $)^{34,35}$ and reran our analyses. Similar to these previous studies, we operationalized potentially mischievous responders as youth who provided extreme responses to two or more (out of seven) questions (e.g., being "not sure" if they have asthma, being "not sure" if they have been to the dentist, eating carrots, potatoes, fruits, or salad four or more times a day).

\section{Results}

The sample included 18,515 bisexual youth $(76.8 \%$ female, $23.2 \%$ male) who were racially/ethnically diverse (40.3\% White, $17.0 \%$ Black, 32.1\% Hispanic, and $10.7 \%$ other races). The mean age was 16.2 years $(\mathrm{SD}=1.2$ years). Endorsement of mental health problems and substance use was high (Table 1): past-year sadness/hopelessness $(62.2 \%)$; past-year suicidal ideation $(44.7 \%)$; lifetime cigarette use $(44.8 \%)$; past-month binge drinking $(23.4 \%)$; lifetime marijuana use $(57.2 \%)$; and lifetime other illicit drug use $(25.7 \%)$. In addition, $32.4 \%$ endorsed past-year in-person bullying and $26.2 \%$ endorsed past-year electronic bullying, which were associated, $\chi^{2}(1)=181.89, p<0.001$.

\section{Bullying (past year)}

Results for bullying are presented in Table 2. Black and Hispanic bisexual youth were less likely to report in-person bullying than White bisexual youth (odds ratio $[\mathrm{OR}]=0.39$, confidence interval [95\% CI] $0.31-0.49$ and $\mathrm{OR}=0.45$, 95\% CI 0.32-0.64, respectively). Black and Hispanic bisexual youth were also less likely to report electronic bullying 
Table 1. Prevalence of Mental Health, Substance Use, and Bullying Victimization as a FunCTION OF RACE/ETHNiCITY

\begin{tabular}{|c|c|c|c|c|c|c|c|c|c|c|}
\hline & \multicolumn{2}{|c|}{$\begin{array}{c}A l l \\
(\mathrm{~N}=18,515)\end{array}$} & \multicolumn{2}{|c|}{$\begin{array}{c}\text { White } \\
(\mathrm{N}=6365)\end{array}$} & \multicolumn{2}{|c|}{$\begin{array}{c}\text { Black } \\
(\mathrm{N}=3570)\end{array}$} & \multicolumn{2}{|c|}{$\begin{array}{c}\text { Hispanic } \\
(\mathrm{N}=5650)\end{array}$} & \multicolumn{2}{|c|}{$\begin{array}{c}\text { Other } \\
(\mathrm{N}=2930)\end{array}$} \\
\hline & $\mathrm{n}$ & $\%$ & $\mathrm{n}$ & $\%$ & $\mathrm{n}$ & $\%$ & $\mathrm{n}$ & $\%$ & $\mathrm{n}$ & $\%$ \\
\hline \multicolumn{11}{|c|}{ Sadness/hopelessness (past year) } \\
\hline Yes & 10,112 & 62.2 & 3864 & 66.5 & 1500 & 45.2 & 3263 & 65.6 & 1485 & 61.4 \\
\hline No & 7453 & 37.8 & 2345 & 33.5 & 1836 & 54.8 & 2134 & 34.4 & 1138 & 38.6 \\
\hline \multicolumn{11}{|c|}{ Suicidal ideation (past year) } \\
\hline Yes & 7237 & 44.7 & 2897 & 49.9 & 1017 & 30.0 & 2226 & 45.3 & 1097 & 46.6 \\
\hline No & 10,056 & 55.3 & 3049 & 50.1 & 2341 & 70.0 & 3165 & 54.7 & 1501 & 53.4 \\
\hline \multicolumn{11}{|c|}{ Cigarette use (lifetime) } \\
\hline Yes & 6342 & 44.8 & 2732 & 50.3 & 822 & 34.1 & 1809 & 44.4 & 979 & 39.9 \\
\hline No & 7764 & 55.2 & 2962 & 49.7 & 1658 & 65.9 & 1951 & 55.6 & 1193 & 60.1 \\
\hline \multicolumn{11}{|c|}{ Binge drinking (past month) } \\
\hline Yes & 4062 & 23.4 & 1461 & 27.2 & 580 & 17.8 & 1414 & 22.8 & 607 & 18.8 \\
\hline No & 13,213 & 76.6 & 4667 & 72.9 & 2645 & 82.2 & 3775 & 77.2 & 2126 & 81.2 \\
\hline \multicolumn{11}{|c|}{ Marijuana use (lifetime) } \\
\hline Yes & 9874 & 57.2 & 3285 & 56.3 & 1954 & 65.6 & 3257 & 58.7 & 1378 & 42.8 \\
\hline No & 7239 & 42.8 & 2826 & 43.7 & 1243 & 34.4 & 1972 & 41.3 & 1198 & 57.2 \\
\hline \multicolumn{11}{|c|}{ Other illicit drug use (lifetime) } \\
\hline Yes & 4800 & 25.7 & 1688 & 26.3 & 751 & 21.0 & 1590 & 27.7 & 771 & 24.7 \\
\hline No & 12,966 & 74.3 & 4569 & 73.7 & 2647 & 79.0 & 3862 & 72.3 & 1888 & 75.3 \\
\hline \multicolumn{11}{|c|}{ In-person bullying (past year) } \\
\hline Yes & 5638 & 32.4 & 2463 & 40.7 & 729 & 21.8 & 1516 & 25.2 & 930 & 39.7 \\
\hline No & 11,842 & 67.6 & 3456 & 59.3 & 2720 & 78.2 & 3828 & 74.8 & 1838 & 60.3 \\
\hline \multicolumn{11}{|c|}{ Electronic bullying (past year) } \\
\hline Yes & 4989 & 26.2 & 2224 & 31.4 & 600 & 18.0 & 1348 & 21.7 & 817 & 33.2 \\
\hline No & 12,691 & 73.8 & 3934 & 68.6 & 2809 & 82.0 & 3965 & 78.4 & 1983 & 66.8 \\
\hline
\end{tabular}

Percentages may exceed 100 due to rounding. In addition, percentages are weighted to account for the complex sampling design of the YRBS. The YRBS data weights adjust for student nonresponse and distribution of students by grade, sex, and race/ethnicity in each jurisdiction. YRBS, Youth Risk Behavior Survey.

than White bisexual youth $(\mathrm{OR}=0.44,95 \%$ CI $0.35-0.56$ and $\mathrm{OR}=0.57,95 \%$ CI $0.41-0.78$, respectively). Sex was not associated significantly with in-person bullying, but female bisexual youth were more likely to report electronic bullying than male bisexual youth $(\mathrm{OR}=1.63,95 \% \mathrm{CI}$
1.25-2.12). The overall $F$-test for the interactions between race/ethnicity and sex was not significant in the in-person bullying model $(p=0.06)$, but it was significant in the electronic bullying model $(p=0.04)$. The interaction between Black race/ethnicity and sex was associated with electronic

Table 2. Racial/Ethnic Differences in Past-Year Bullying Victimization Among Bisexual Youth

\begin{tabular}{|c|c|c|c|c|c|c|}
\hline & \multirow{2}{*}{\multicolumn{2}{|c|}{$\begin{array}{c}\text { In-person bullying } \\
\text { Main effects }\end{array}$}} & \multicolumn{4}{|c|}{ Electronic bullying } \\
\hline & & & \multicolumn{2}{|c|}{ Main effects } & \multicolumn{2}{|c|}{ Interaction effects } \\
\hline & $O R$ & $95 \% C I$ & OR & $95 \% C I$ & $O R$ & $95 \% C I$ \\
\hline \multicolumn{7}{|l|}{ Race/ethnicity } \\
\hline White & Ref. & & Ref. & & Ref. & \\
\hline Black & 0.39 & $0.31-0.49$ & 0.44 & $0.35-0.56$ & 0.86 & $0.51-1.44$ \\
\hline Hispanic & 0.45 & $0.32-0.64$ & 0.57 & $0.41-0.78$ & 0.94 & $0.52-1.71$ \\
\hline Other & 0.92 & $0.56-1.52$ & 1.04 & $0.58-1.87$ & 1.03 & $0.55-1.91$ \\
\hline \multicolumn{7}{|l|}{ Sex } \\
\hline Male & Ref. & & Ref. & & Ref. & \\
\hline Female & 1.06 & $0.82-1.36$ & 1.63 & $1.25-2.12$ & 2.11 & $1.46-3.06$ \\
\hline \multicolumn{7}{|l|}{ Interaction effects } \\
\hline Black $\times \operatorname{sex}$ & & & & & 0.45 & $0.25-0.82$ \\
\hline Hispanic $\times$ sex & & & & & 0.54 & $0.29-1.01$ \\
\hline Other $\times$ sex & & & & & 1.01 & $0.38-2.71$ \\
\hline
\end{tabular}

Bold font indicates significance at $p<0.05$; all models control for age and survey year. Interaction effects are not presented for in-person bullying because the overall $F$-test for the interaction between race/ethnicity and sex was not significant.

CI, confidence interval; OR, odds ratio. 
bullying ( $\mathrm{OR}=0.45,95 \%$ CI $0.25-0.82)$. Black bisexual female youth were less likely to report electronic bullying than White bisexual female youth $(\mathrm{OR}=0.39,95 \% \mathrm{CI}$ 0.30-0.51), but electronic bullying did not differ significantly between Black and White bisexual male youth $(\mathrm{OR}=0.86,95 \%$ CI 0.51-1.44).

\section{Sadness/hopelessness and suicidal ideation (past year)}

Results for sadness/hopelessness and suicidal ideation are presented in Table 3. Black bisexual youth were less likely to report sadness/hopelessness $(\mathrm{OR}=0.45,95 \%$ CI 0.36-0.56) and suicidal ideation $(\mathrm{OR}=0.49,95 \%$ CI $0.36-0.66)$ than White bisexual youth. Female bisexual youth were more likely to report sadness/hopelessness than male bisexual youth $(\mathrm{OR}=1.81,95 \% \mathrm{CI} 1.49-2.19)$, but sex was not associated significantly with suicidal ideation. The overall $F$-test for the interactions between race/ethnicity and sex was not significant in either model ( $p=0.34$ in both models). In-person and electronic bullying were associated with sadness/hopelessness $(\mathrm{OR}=2.26,95 \%$ CI $1.75-2.93$ and $\mathrm{OR}=1.78,95 \%$ CI 1.38-2.30, respectively) and suicidal ideation $(\mathrm{OR}=1.90,95 \% \mathrm{CI} 1.37-2.63$ and $\mathrm{OR}=1.6395 \% \mathrm{CI}$ 1.19-2.23, respectively). The main effects of race/ethnicity and sex remained significant after controlling for bullying.

\section{Cigarette use (lifetime)}

Results for cigarette use are presented in Table 4. Black bisexual youth were less likely to report cigarette use than White bisexual youth $(\mathrm{OR}=0.48,95 \%$ CI $0.33-0.70)$. Sex was not associated significantly with cigarette use. The overall $F$-test for the interactions between race/ethnicity and sex was significant $(p<0.001)$. The interaction between Black race/ethnicity and sex was significant $(\mathrm{OR}=0.20,95 \% \mathrm{CI}$ $0.10-0.38$ ). Black bisexual female youth were less likely to report cigarette use than White bisexual female youth $(\mathrm{OR}=0.34,95 \%$ CI $0.23-0.48)$, but cigarette use did not differ significantly between Black and White bisexual male youth $(\mathrm{OR}=1.69,95 \%$ CI $0.87-3.28)$. Only electronic bullying was associated with cigarette use $(\mathrm{OR}=1.87,95 \% \mathrm{CI}$
1.48-2.36). The main effect of race/ethnicity and the interaction between Black race/ethnicity and sex remained significant after controlling for bullying.

\section{Binge drinking (past month)}

Results for binge drinking are presented in Table 5. Black and Other race/ethnicity bisexual youth were less likely to report binge drinking than White bisexual youth $(\mathrm{OR}=0.58$, $95 \%$ CI $0.39-0.87$ and OR $=0.65,95 \%$ CI $0.43-0.98$, respectively). Female bisexual youth were less likely to report binge drinking than male bisexual youth $(\mathrm{OR}=0.83,95 \%$ CI $0.71-0.98)$. The overall $F$-test for the interactions between race/ethnicity and sex was significant $(p=0.03)$. The interaction between Black race/ethnicity and sex was significant $(\mathrm{OR}=0.31,95 \%$ CI 0.14-0.66). Black bisexual female youth were less likely to report binge drinking than White bisexual female youth $(\mathrm{OR}=0.44,95 \%$ CI $0.31-0.61)$, but binge drinking did not differ significantly between Black and White bisexual male youth $(\mathrm{OR}=1.43$, 95\% CI 0.63 3.24). Only electronic bullying was associated with binge drinking $(\mathrm{OR}=1.61,95 \% \mathrm{CI} 1.11-2.35)$. The main effects of Black race/ethnicity and sex, as well as their interaction, became nonsignificant after controlling for bullying. The main effect of Other race/ethnicity remained significant after controlling for bullying, but only in the main effects model.

\section{Marijuana use (lifetime)}

Results for marijuana use are presented in Table 6. Black bisexual youth were more likely to report marijuana use than White bisexual youth $(\mathrm{OR}=1.45,95 \%$ CI 1.12-1.87). Other race/ethnicity bisexual youth were less likely to report marijuana use than White bisexual youth $(\mathrm{OR}=0.59,95 \% \mathrm{CI}$ $0.37-0.94)$. Female bisexual youth were more likely to report marijuana use than male bisexual youth $(\mathrm{OR}=1.68,95 \% \mathrm{CI}$ 1.23-2.30). The overall $F$-test for the interactions between race/ethnicity and sex was not significant $(p=0.07)$. Only electronic bullying was associated with marijuana use $(\mathrm{OR}=1.67,95 \%$ CI 1.19-2.34). The main effects of race/

Table 3. Racial/Ethnic Differences in Past-Year Sadness/Hopelessness and Suicidal Ideation Among Bisexual Youth

\begin{tabular}{|c|c|c|c|c|c|c|c|c|}
\hline & \multicolumn{4}{|c|}{ Sadness/hopelessness } & \multicolumn{4}{|c|}{ Suicidal ideation } \\
\hline & \multicolumn{2}{|c|}{ Main effects } & \multicolumn{2}{|c|}{ Main effects+bullying } & \multicolumn{2}{|c|}{ Main effects } & \multicolumn{2}{|c|}{ Main effects+bullying } \\
\hline & OR & $95 \% C I$ & $O R$ & $95 \% C I$ & $O R$ & $95 \% C I$ & $O R$ & $95 \% C I$ \\
\hline \multicolumn{9}{|l|}{ Race/ethnicity } \\
\hline White & Ref. & & Ref. & & Ref. & & Ref. & \\
\hline Black & 0.45 & $0.36-0.56$ & $\mathbf{0 . 5 3}$ & $0.41-0.68$ & 0.49 & $0.36-0.66$ & 0.59 & $0.41-0.85$ \\
\hline Hispanic & 0.78 & $0.57-1.05$ & 0.85 & $0.59-1.21$ & 0.85 & $0.64-1.13$ & 0.94 & $0.66-1.35$ \\
\hline Other & 0.80 & $0.58-1.11$ & 0.87 & $0.59-1.30$ & 0.88 & $0.62-1.26$ & 0.92 & $0.61-1.38$ \\
\hline \multicolumn{9}{|l|}{ Sex } \\
\hline Male & Ref. & & Ref. & & Ref. & & Ref. & \\
\hline Female & 1.81 & 1.49-2.19 & 1.95 & $1.55-2.47$ & 1.34 & $0.99-1.81$ & 1.42 & $0.97-2.06$ \\
\hline \multicolumn{9}{|l|}{ Bullying } \\
\hline In-person & & & 2.26 & $1.75-2.93$ & & & 1.90 & $1.37-2.63$ \\
\hline Electronic & & & 1.78 & $1.38-2.30$ & & & 1.63 & $1.19-2.23$ \\
\hline
\end{tabular}

Bold font indicates significance at $p<0.05$; models control for age and survey year. Interaction effects are not presented because the overall $F$-tests for the interactions between race/ethnicity and sex were not significant. 
Table 4. Racial/Ethnic Differences in Lifetime Cigarette Use Among Bisexual Youth

\begin{tabular}{|c|c|c|c|c|c|c|c|c|}
\hline & \multicolumn{2}{|c|}{ Main effects } & \multicolumn{2}{|c|}{ Main effects + bullying } & \multicolumn{2}{|c|}{ Interaction effects } & \multicolumn{2}{|c|}{ Interaction effects + bullying } \\
\hline & $O R$ & $95 \% C I$ & $O R$ & $95 \% C I$ & $O R$ & $95 \% C I$ & $O R$ & $95 \% C I$ \\
\hline \multicolumn{9}{|l|}{ Race/ethnicity } \\
\hline White & Ref. & & Ref. & & Ref. & & Ref. & \\
\hline Black & 0.48 & $0.33-0.70$ & 0.48 & $0.31-0.76$ & 1.69 & $0.87-3.28$ & 1.70 & $0.76-3.83$ \\
\hline Hispanic & 0.81 & $0.60-1.10$ & 0.94 & $0.64-1.38$ & 1.11 & $0.51-2.43$ & 1.21 & $0.45-3.26$ \\
\hline Other & 0.66 & $0.36-1.22$ & 0.63 & $0.30-1.31$ & 0.87 & $0.48-1.59$ & 0.65 & $0.38-1.13$ \\
\hline \multicolumn{9}{|l|}{ Sex } \\
\hline Male & Ref. & & Ref. & & Ref. & & Ref. & \\
\hline Female & 1.26 & $0.92-1.72$ & 1.27 & $0.85-1.90$ & 1.85 & $1.21-2.82$ & 1.76 & $1.06-2.92$ \\
\hline \multicolumn{9}{|l|}{ Bullying } \\
\hline In-person & & & 1.21 & $0.87-1.67$ & & & 1.20 & $0.86-1.66$ \\
\hline Electronic & & & 1.87 & $1.48-2.36$ & & & 1.83 & $1.44-2.33$ \\
\hline \multicolumn{9}{|l|}{ Interaction effects } \\
\hline Black $\times$ sex & & & & & 0.20 & $0.10-0.38$ & 0.21 & 0.10-0.43 \\
\hline Hispanic $\times$ sex & & & & & 0.66 & $0.27-1.64$ & 0.76 & $0.26-2.19$ \\
\hline Other $\times$ sex & & & & & 0.69 & $0.30-1.61$ & 0.96 & $0.43-2.19$ \\
\hline
\end{tabular}

Bold font indicates significance at $p<0.05$; models control for age and survey year.

ethnicity and sex remained significant after controlling for bullying.

\section{Other illicit drug use (lifetime)}

Results for other illicit drug use are presented in Table 7. Black bisexual youth were less likely to report illicit drug use than White bisexual youth $(\mathrm{OR}=0.74,95 \%$ CI $0.56-0.97)$. Female bisexual youth were less likely to report illicit drug use than male bisexual youth $(\mathrm{OR}=0.74,95 \%$ CI $0.57-0.96)$. The overall $F$-test for the interactions between race/ethnicity and sex was significant $(p=0.01)$. The interaction between Black race/ethnicity and sex was significant $(\mathrm{OR}=0.43$, 95\% CI 0.22-0.85). Black bisexual female youth were less likely to report illicit drug use than White bisexual female youth ( $\mathrm{OR}=0.59,95 \%$ CI $0.42-0.82)$, but illicit drug use did not differ significantly between Black and White bisexual male youth $(\mathrm{OR}=1.37,95 \%$ CI 0.77 2.44). In-person and electronic bullying were associated with illicit drug use $(\mathrm{OR}=1.61,95 \% \mathrm{CI} 1.20-2.16$ and $\mathrm{OR}=1.78,95 \%$ CI $1.40-2.28$, respectively). The main effects of race/ethnicity and sex, as well as their interaction, became nonsignificant after controlling for bullying.

\section{Supplementary analyses}

Compared with Black bisexual youth, Hispanic bisexual youth were more likely to report sadness/hopelessness

Table 5. Racial/Ethnic Differences in Binge Drinking Among Bisexual Youth

\begin{tabular}{|c|c|c|c|c|c|c|}
\hline & \multicolumn{2}{|c|}{ Main effects } & \multicolumn{2}{|c|}{ Main effects + bullying } & \multicolumn{2}{|c|}{ Interaction effects } \\
\hline & OR & $95 \% C I$ & OR & $95 \% C I$ & $O R$ & $95 \% C I$ \\
\hline \multicolumn{7}{|l|}{ Race/ethnicity } \\
\hline White & Ref. & & Ref. & & Ref. & \\
\hline Black & 0.58 & 0.39-0.87 & 0.62 & $0.38-1.01$ & 1.37 & $0.58-3.22$ \\
\hline Hispanic & 0.82 & $0.60-1.12$ & 0.84 & $0.58-1.22$ & 0.97 & $0.58-1.63$ \\
\hline Other & 0.65 & $0.43-0.98$ & 0.52 & $0.30-0.88$ & 0.78 & $0.38-1.61$ \\
\hline \multicolumn{7}{|l|}{ Sex } \\
\hline Male & Ref. & & Ref. & & Ref. & \\
\hline Female & 0.83 & $0.71-0.98$ & 0.91 & $0.57-1.45$ & 1.26 & $0.78-2.05$ \\
\hline \multicolumn{7}{|l|}{ Bullying } \\
\hline In-person & & & 1.23 & $0.90-1.70$ & & \\
\hline Electronic & & & 1.61 & $1.11-2.35$ & & \\
\hline \multicolumn{7}{|l|}{ Interaction effects } \\
\hline Black $\times$ sex & & & & & 0.31 & $0.14-0.66$ \\
\hline Hispanic $\times$ sex & & & & & 0.84 & $0.44-1.60$ \\
\hline Other $\times$ sex & & & & & 0.72 & $0.31-1.63$ \\
\hline
\end{tabular}

Bold font indicates significance at $p<0.05$; models control for age and survey year. Interaction effects controlling for bullying are not presented because the overall $F$-test for the interaction between race/ethnicity and sex was not significant in that model. 
Table 6. Racial/Ethnic Differences in MariJuana Use Among Bisexual Youth

\begin{tabular}{|c|c|c|c|c|}
\hline & \multicolumn{2}{|c|}{ Marijuana use } & \multicolumn{2}{|c|}{ Marijuana use + bullying } \\
\hline & OR & $95 \% C I$ & $O R$ & $95 \% C I$ \\
\hline \multicolumn{5}{|l|}{ Race/ethnicity } \\
\hline White & Ref. & & Ref. & \\
\hline Black & 1.45 & 1.12-1.87 & 1.64 & $1.20-2.24$ \\
\hline Hispanic & 1.15 & $0.85-1.55$ & 1.28 & $0.90-1.83$ \\
\hline Other & 0.59 & $0.37-0.94$ & 0.52 & $0.29-0.94$ \\
\hline \multicolumn{5}{|l|}{ Sex } \\
\hline Male & Ref. & & Ref. & \\
\hline Female & 1.68 & $1.23-2.30$ & 1.79 & $1.22-2.61$ \\
\hline \multicolumn{5}{|l|}{ Bullying } \\
\hline In-person & & & 1.13 & $0.84-1.51$ \\
\hline Electronic & & & 1.67 & 1.19-2.34 \\
\hline
\end{tabular}

Bold font indicates significance at $p<0.05$; models control for age and survey year. Interaction effects are not presented because the overall $F$-tests for the interactions between race/ethnicity and sex were not significant.

$(\mathrm{OR}=1.74,95 \%$ CI 1.25-2.41), suicidal ideation $(\mathrm{OR}=1.74$, 95\% CI 1.29-2.34), cigarette use $(\mathrm{OR}=1.69$, 95\% CI 1.24 $2.31)$, and other illicit drug use $(\mathrm{OR}=1.51,95 \%$ CI 1.19 1.91). In addition, compared with Black bisexual youth, Other race/ethnicity bisexual youth were more likely to report sadness/hopelessness $(\mathrm{OR}=1.80,95 \%$ CI 1.28-2.51) and suicidal ideation $(\mathrm{OR}=1.81,95 \%$ CI $1.28-2.54)$, but they were less likely to report marijuana use $(\mathrm{OR}=0.41,95 \%$ CI 0.25-0.67). There were significant Hispanic race/ethnicity by sex interaction effects for cigarette use, binge drinking, and other illicit drug use, but none of the follow-up comparisons was significant. There were also significant Other race/ethnicity by sex interaction effects for cigarette use and other illicit drug use, but none of the follow-up comparisons were significant. All of the significant effects remained significant after controlling for bullying.

\section{Sensitivity analyses}

A total of 631 bisexual youth $(3.4 \%)$ were identified as potentially mischievous responders. We excluded these youth from the analytic sample and reran our analyses. The results were remarkably similar. The only exception was that Hispanic bisexual youth were more likely to report other illicit drug use than White bisexual youth after controlling for bullying $(\mathrm{OR}=1.34,95 \% \mathrm{CI} 1.01-1.76)$.

\section{Discussion}

Bisexual youths' endorsement of sadness/hopelessness, suicidal ideation, and substance use was remarkably high. Data from the 2017 YRBS revealed much lower endorsement among heterosexual youth compared with the bisexual youth in our sample: past-year sadness/hopelessness $(27.5 \%$ vs. $62.2 \%$ ), past-year suicidal ideation (13.3\% vs. $44.7 \%$ ), lifetime cigarette use $(28.2 \%$ vs. $44.8 \%)$, past-month binge drinking (13.2\% vs. 23.4\%), and lifetime marijuana use $(35.2 \%$ vs. $57.2 \%){ }^{36}$ These findings highlight the critical need for targeted prevention and intervention efforts focused on bisexual youth.

Black bisexual youth were less likely to report sadness/hopelessness and suicidal ideation than White bisexual youth. In supplementary analyses, Black bisexual youth were also less likely to report sadness/hopelessness and suicidal ideation than Hispanic and Other race/ethnicity bisexual youth. In addition, Black bisexual female youth were less likely to report substance use (except marijuana) than White bisexual female youth. In supplementary analyses, Black bisexual youth were also less likely to report cigarette use and other illicit drug use than Hispanic bisexual youth. These findings are generally consistent with research on high school-aged youth in the general population ${ }^{36}$ and SM youth in general, ${ }^{22,24}$ and they may suggest that Black bisexual youth experience greater resilience in the face of stigma than White and Hispanic bisexual youth. This is consistent with the resilience perspective,

Table 7. Racial/Ethnic Differences in Other Illicit Drug Use Among Bisexual Youth

\begin{tabular}{|c|c|c|c|c|c|c|}
\hline & \multicolumn{2}{|c|}{ Main effects } & \multicolumn{2}{|c|}{ Main effects + bullying } & \multicolumn{2}{|c|}{ Interaction effects } \\
\hline & $O R$ & $95 \% C I$ & $O R$ & $95 \% C I$ & $O R$ & $95 \% C I$ \\
\hline \multicolumn{7}{|l|}{ Race/ethnicity } \\
\hline White & Ref. & & Ref. & & Ref. & \\
\hline Black & 0.74 & $0.56-0.97$ & 0.78 & $0.55-1.10$ & 1.37 & $0.77-2.44$ \\
\hline Hispanic & 1.11 & $0.88-1.40$ & 1.29 & $0.96-1.74$ & 0.86 & $0.59-1.27$ \\
\hline Other & 0.95 & $0.53-1.68$ & 0.84 & $0.44-1.61$ & 0.73 & $0.41-1.30$ \\
\hline \multicolumn{7}{|l|}{ Sex } \\
\hline Male & Ref. & & Ref. & & Ref. & \\
\hline Female & 0.74 & $0.57-0.96$ & 0.76 & $0.55-1.05$ & 0.73 & $0.49-1.07$ \\
\hline \multicolumn{7}{|l|}{ Bullying } \\
\hline In-person & & & 1.61 & $1.20-2.16$ & & \\
\hline Electronic & & & 1.78 & $1.40-2.28$ & & \\
\hline \multicolumn{7}{|l|}{ Interaction effects } \\
\hline Black $\times$ sex & & & & & 0.43 & $0.22-0.85$ \\
\hline Hispanic $\times$ sex & & & & & 1.39 & $0.82-2.38$ \\
\hline Other $\times \operatorname{sex}$ & & & & & 1.40 & $0.59-3.33$ \\
\hline
\end{tabular}

Bold font indicates significance at $p<0.05$; models control for age and survey year. Interaction effects controlling for bullying are not presented because the overall $F$-test for the interaction between race/ethnicity and sex was not significant in that model. 
suggesting that Black bisexual youth may possess unique strengths (e.g., higher religiosity and skills for coping with racism) that contribute to resilience. ${ }^{19}$

Although bisexual people are less likely to disclose their sexual identity than gay/lesbian people, ${ }^{37,38} \mathrm{SM}$ people of color are also less likely to disclose their sexual identity than White SM people. ${ }^{19,39}$ Given that youth who come out are more susceptible to victimization, ${ }^{40}$ and that being more open about one's bisexual identity is associated with depression and substance use, ${ }^{41,42}$ Black bisexual youth may have reported better mental health and less substance use because they may have been less open about their sexual identity. Bisexual men are also less likely to disclose their sexual identity than bisexual women, ${ }^{38}$ which could explain why racial/ethnic differences in substance use were only significant for female youth. Although our findings provide support for the resilience perspective, they suggest that it may not extend to all bisexual youth of color. Scholars have acknowledged the limitations of broad categories such as "youth of color," which can mask important differences between groups. ${ }^{24}$ Our data cannot explain why Black, but not Hispanic and Other race/ethnicity, bisexual youth reported better mental health and less substance use than their White peers. It will be important for future research to examine racial/ethnic differences in factors that are hypothesized to contribute to resilience among SM people of color, which could help explain differences in health outcomes.

Although Black and Hispanic bisexual youth were less likely to endorse bullying than White bisexual youth, most of the racial/ethnic differences in health remained significant after controlling for bullying. As such, bullying does not appear to account for racial/ethnic differences in health among bisexual youth. Of note, electronic bullying was associated significantly with all of the health outcomes, whereas in-person bullying was only associated significantly with half of the outcomes. These findings highlight the importance of assessing electronic bullying, which may be a more robust predictor of health than in-person bullying in present times. These findings also support the need for antibullying policies and programs in schools, which have the potential to reduce bullying and improve the health of youth.

In contrast to most of our findings, Black bisexual youth were more likely to report marijuana use than White bisexual youth. These findings are consistent with evidence that Black SM male youth report more marijuana use than White SM male youth ${ }^{8}$ and that marijuana use has increased among Black youth and decreased among White youth in recent years. ${ }^{43}$ It is unclear why Black bisexual female youth generally reported less substance use than their White peers, whereas Black bisexual youth reported more marijuana use than their White peers. It will be important to continue to examine the health of bisexual youth at the intersection of sex and race/ethnicity.

\section{Limitations}

First, the number of bisexual male youth in each racial/ethnic group was lower than the number of bisexual female youth. However, there were still more than 600 bisexual male youth in the smallest racial/ethnic group. Second, we were unable to examine specific racial/ethnic groups other than Black, Hispanic, and White. Third, the main effect of Other race/ethnicity became nonsignificant in the interaction models for binge drinking and marijuana use, but the interaction between Other race/ethnicity and sex was not significant in either model. Given that the Other race/ethnicity group included youth who identified as American Indian or Alaska Native, Asian, and Native Hawaiian or other Pacific Islander, it will be important for future research to examine the similarities and differences among these groups. Fourth, our measures of mental health and substance use were based on self-report, and future studies could use diagnostic interviews to examine racial/ethnic differences in psychiatric disorders. Finally, our measures of bullying did not account for perceived cause (e.g., sexual orientation or race/ethnicity). Black and Hispanic bisexual youth may have been less likely to report bullying than White bisexual youth because our measures did not assess racial discrimination. It will be important for future research to examine the extent to which different systems of oppression influence the health of bisexual youth.

\section{Conclusion}

The high rates of mental health problems and substance use in our sample highlight the critical need for prevention and intervention services for bisexual youth. Our findings also reveal the heterogeneity of bisexual youth and the need to consider multiple marginalized identities to understand their disparities. Given that bisexual female youth were more likely to report sadness/hopeless, marijuana use, and electronic bullying, whereas bisexual male youth were more likely to report binge drinking, different intervention targets may be more salient for bisexual youth depending on their sex. Although Black bisexual youth generally reported fewer negative health outcomes than White bisexual youth, additional research is needed to understand the factors that contribute to these racial/ethnic differences. These findings support the need for antibullying policies and programs, but they also suggest that additional factors contribute to racial/ethnic differences in health among bisexual youth. Given the dearth of research on race/ethnicity in this population, it will be important to continue to examine the ways in which intersecting identities shape bisexual youths' experiences and health.

\section{Acknowledgments}

This research was supported by a grant from the National Institute on Alcohol Abuse and Alcoholism (R01AA024409; PI: Gregory Phillips II). B.A.F.'s time was also supported by a grant from the National Institute on Drug Abuse (K08DA045575; PI: B.A.F.). The authors acknowledge the Centers for Disease Control and Prevention for its role in developing the YRBS.

\section{Disclaimer}

The content is solely the responsibility of the authors and does not necessarily represent the official views of the funding agency. 


\section{Author Disclosure Statement}

No competing financial interests exist.

\section{Supplementary Material}

Supplementary Table S1

\section{References}

1. Marshal MP, Dietz LJ, Friedman MS, et al.: Suicidality and depression disparities between sexual minority and heterosexual youth: A meta-analytic review. J Adolesc Health 2011;49:115-123.

2. Marshal MP, Friedman MS, Stall R, et al.: Sexual orientation and adolescent substance use: A meta-analysis and methodological review. Addiction 2008;103:546-556.

3. Russell ST, Fish JN: Mental health in lesbian, gay, bisexual, and transgender (LGBT) youth. Annu Rev Clin Psychol 2016;12:465-487.

4. Marshal MP, Dermody SS, Cheong J, et al.: Trajectories of depressive symptoms and suicidality among heterosexual and sexual minority youth. J Youth Adolesc 2013;42: 1243-1256.

5. Caputi TL, Smith D, Ayers JW: Suicide risk behaviors among sexual minority adolescents in the United States, 2015. JAMA 2017;318:2349-2351.

6. Cardom R, Rostosky S, Danner F: Does “it get better" for depressed sexual minority youth in young adulthood? J Adolesc Health 2013;53:671-673.

7. Trocki KF, Drabble LA, Midanik LT: Tobacco, marijuana, and sensation seeking: Comparisons across gay, lesbian, bisexual, and heterosexual groups. Psychol Addict Behav 2009;23:620-631.

8. Newcomb ME, Ryan DT, Greene GJ, et al.: Prevalence and patterns of smoking, alcohol use, and illicit drug use in young men who have sex with men. Drug Alcohol Depend 2014;141:65-71.

9. Azagba S, Asbridge M, Langille D, Baskerville B: Disparities in tobacco use by sexual orientation among high school students. Prev Med 2014;69:307-311.

10. Corliss HL, Rosario M, Birkett MA, et al.: Sexual orientation disparities in adolescent cigarette smoking: Intersections with race/ethnicity, gender, and age. Am J Public Health 2014;104:1137-1147.

11. Dai HY: Tobacco product use among lesbian, gay, and bisexual adolescents. Pediatrics 2017;139:pii:e20163276.

12. Phillips G 2nd, Turner B, Salamanca P, et al.: Victimization as a mediator of alcohol use disparities between sexual minority subgroups and sexual majority youth using the 2015 National Youth Risk Behavior Survey. Drug Alcohol Depend 2017; 178:355-362.

13. Talley AE, Hughes TL, Aranda F, et al.: Exploring alcoholuse behaviors among heterosexual and sexual minority adolescents: Intersections with sex, age, and race/ethnicity. Am J Public Health 2014;104:295-303.

14. Bauer GR: Incorporating intersectionality theory into population health research methodology: Challenges and the potential to advance health equity. Soc Sci Med 2014;110:10-17.

15. Bowleg L: The problem with the phrase women and minorities: Intersectionality-an important theoretical framework for public health. Am J Public Health 2012;102:1267-1273.

16. Crenshaw KW: Mapping the margins: Intersectionality, identity politics, and violence against women of color. Stanford Law Rev 1991;43:1241-1299.
17. Greene B: Lesbian women of color: Triple jeopardy. J Lesbian Stud 1996;1:109-147.

18. King DK: Multiple jeopardy, multiple consciousness: The context of a Black feminist ideology. Signs 2016;14: $42-72$.

19. Moradi B, Wiseman MC, DeBlaere C, et al.: LGB of color and White individuals' perceptions of heterosexist stigma, internalized homophobia, and outness: Comparisons of levels and links. Couns Psychol 2010;38:397-424.

20. Barnes DM, Meyer IH: Religious affiliation, internalized homophobia, and mental health in lesbians, gay men, and bisexuals. Am J Orthopsychiatry 2012;82:505-515.

21. Politt AM, Mallory AB, Fish JN: Homophobic bullying and sexual minority youth alcohol use: Do sex and race/ethnicity matter? LGBT Health 2018;5:412-420.

22. Burns MN, Ryan DT, Garofalo R, et al.: Mental health disorders in young urban sexual minority men. J Adolesc Health 2015;56:52-58.

23. Toomey RB, Huynh VW, Jones SK, et al.: Sexual minority youth of color: A content analysis and critical review of the literature. J Gay Lesbian Ment Health 2017;21:3-31.

24. Bostwick WB, Meyer I, Aranda F, et al.: Mental health and suicidality among racially/ethnically diverse sexual minority youths. Am J Public Health 2014;104:11291136.

25. Lytle MC, De Luca SM, Blosnich JR: The influence of intersecting identities on self-harm, suicidal behaviors, and depression among lesbian, gay, and bisexual individuals. Suicide Life Threat Behav 2014;44:384-391.

26. Berlan ED, Corliss HL, Field AE, et al.: Sexual orientation and bullying among adolescents in the Growing Up Today Study. J Adolesc Health 2010;46:366-371.

27. O’Malley Olsen E, Kann L, Vivolo-Kantor A, et al.: School violence and bullying among sexual minority high school students, 2009-2011. J Adolesc Health 2014;55:432-438.

28. Abreu RL, Kenny MC: Cyberbullying and LGBTQ youth: A systematic literature review and recommendations for prevention and intervention. J Child Adolesc Trauma 2018;11:81-97.

29. Collier KL, van Beusekom G, Bos HM, Sandfort TG: Sexual orientation and gender identity/expression related peer victimization in adolescence: A systematic review of associated psychosocial and health outcomes. J Sex Res 2013;50: 299-317.

30. Hanlon B: 2003 Youth Risk Behavior Survey Results. Malden, MA: Massachusetts Department of Education, 2004.

31. Russell ST, Ryan C, Toomey RB, et al.: Lesbian, gay, bisexual, and transgender adolescent school victimization: Implications for young adult health and adjustment. J Sch Health 2011;81:223-230.

32. GLSEN, CiPHR, \& CCRC: Out online: The experiences of lesbian, gay, bisexual and transgender youth on the Internet. New York, NY: GLSEN, 2013.

33. Brener ND, Kann L, Shanklin S, et al.: Methodology of the Youth Risk Behavior Surveillance System-2013. MMWR Recomm Rep 2013;62:1-23.

34. Robinson-Cimpian JP: Inaccurate estimate of disparities due to mischievous responders: Several suggestions to assess conclusions. Educ Res 2014;43:171-185.

35. Cimpian JR, Timmer JD, Birkett MA, et al.: Bias from potentially mischievous responders on large-scale estimates of lesbian, gay, bisexual, or questioning (LGBQ)-heterosexual youth health disparities. Am J Public Health 2018;108: S258-S265. 
36. Kann L, McManus T, Harris WA, et al.: Youth Risk Behavior Surveillance-United States, 2017. MMWR Surveill Summ 2018;67:1-114.

37. Balsam KF, Mohr JJ: Adaptation to sexual orientation stigma: A comparison of bisexual and lesbian/gay adults. J Couns Psychol 2007;54:306-319.

38. Pew Research Center: A Survey of LGBT Americans: Attitudes, Experiences and Values in Changing Times. Pew Research Center, Washington, DC, 2013.

39. Balsam KF, Molina Y, Blayney JA, et al.: Racial/ethnic differences in identity and mental health outcomes among young sexual minority women. Cultur Divers Ethnic Minor Psychol 2015;21:380-390.

40. Russell ST, Toomey RB, Ryan C, Diaz RM: Being out at school: The implications for school victimization and young adult adjustment. Am J Orthopsychiatry 2014;84:635-643.

41. Feinstein BA, Dyar C, Li DH, et al.: The longitudinal associations between outness and health outcomes among gay/lesbian versus bisexual emerging adults. Arch Sex Behav 2018. DOI: 10.1007/s10508-018-1221-8.
42. Feinstein BA, Dyar C, London B: Are outness and community involvement risk or protective factors for alcohol and drug abuse among sexual minority women? Arch Sex Behav 2017;46:1411-1423.

43. Johnston LD, Miech RA, O'Malley PM, et al.: Monitoring the Future: National Survey Results on Drug Use 19752017: Overview, Key Findings on Adolescent Drug Use. Ann Arbor, MI: The University of Michigan Institute for Social Research, 2018.

Address correspondence to:

Brian A. Feinstein, PhD

Institute for Sexual and Gender Minority

Health and Wellbeing

Northwestern University

625 N. Michigan Avenue Suite 1400

Chicago, IL 60611

E-mail: brian.feinstein@northwestern.edu 